Original Research Paper

\title{
Investigating Bio-Char as Flow Modifier and Water Treatment Agent for Sustainable Pavement Design
}

\author{
${ }^{1}$ Renaldo Walters, ${ }^{2}$ Shamim A. Begum, ${ }^{1}$ Elham H. Fini and ${ }^{1}$ Taher M. Abu-Lebdeh \\ ${ }^{1}$ Department of Civil, Architectural and Environmental Engineering, \\ North Carolina A\&T State University, Greensboro, NC, USA \\ ${ }^{2}$ Department of Chemical Engineering, Tuskegee University, Tuskegee, AL, USA
}

Article history

Received: 17-01-2015

Revised: 04-02-2015

Accepted: 04-02-2015

Corresponding Author:

Taher M. Abu-Lebdeh

Department of Civil, Architectural and Environmental Engineering,

North Carolina A\&T State

University, Greensboro, NC, USA

Email: taher@ncat.edu

\begin{abstract}
The life expectancy of Asphalt Binder (AB) has been negatively impacted by the harsh bombardment of Ultraviolet (UV) rays. UV rays cause asphalt to oxidize faster, which results in the deterioration of asphalt's rheological characteristics that can lead to pavement distresses. This paper investigates merits of bio-char to improve asphalt aging susceptibility by blending one control binder (PG 64-22) and two bio-modified binder at concentrations of 3 and $6 \%$ individually; the specimens were then analyzed in terms of their rheological characterization before and after aging. Rolling Thin Film Oven (RTFO) method was used to age all specimens, aged and un-aged samples were then tested using a Rotational Viscometer (RV) to evaluate the changes in their rheological behavior before and after aging as a result of aforementioned modifications. This paper also looks at the chemical composition and elemental analysis of bio-char along with biochars' ability to absorb chromium. A sorption procedure was used to determine whether or not bio-char can be used to absorb chromium. The highest chromium removal occurred at a $\mathrm{pH}$ value of 5.5. Bio-char was used to improve dispersion and liquid retention, while enhancing oxidation resistance.
\end{abstract}

Keywords: Bio-Char, Aging, Asphalt Binder, Rotational Viscometer

\section{Introduction}

The chemical and physiochemical mechanisms involved in asphalt oxidative aging have been the subject of numerous research investigations and much speculation for many decades. In this study bio-char at two different concentrations, 3 and $6 \%$ by weight of dry mass is blended with asphalt binder to investigate rheological characteristics and aging susceptibility. The selected asphalt binder for this study is PG 64-22, which is commonly used in the state of North Carolina. This bitumen is petroleum based refined product. Typical heating temperature of the bitumen is $177^{\circ} \mathrm{C}$ with its flash point being $325^{\circ} \mathrm{C}$. Preferred storage temperatures range between 140 to $168^{\circ} \mathrm{C}$. Unnecessarily high temperatures result in increased hardening, oxidation and heating cost. PG 64-22 is primarily used for paving in both new construction and pavement rehabilitation (U.S. Oil and Refining Co.).
Due to the increasing concerns about the service life of asphalt binders for oxidative aging, this study strives to decrease the rate of asphalt oxidation, which is one of the main causes of pavement distresses. This in turn will enhance rheological behavior of asphalt and extend pavement service life by reducing asphalt aging susceptibility. Asphalt binder's physiochemical properties determine how it will perform as a constituent in Asphalt Concrete (AC) pavement. Although asphalt binder's viscosity grading is still common, new binder tests and specifications have been developed to more accurately characterize asphalt binders for use in AC pavements. These tests and specifications are specifically designed to address AC pavement performance parameters such as rutting, fatigue cracking and thermal cracking. Over the years there have been various attempts to modify asphalt binder in order to improve its overall performance. The inclusion of various additives such as Styrene Butadiene Styrene (SBS), Styrene 
Butadiene Rubber (SBR), Ethylene Glycidyl Acrylate (EGA) terpolymer, crumb rubber, organomontmorillonite, waste tire rubber, fibers and waste fibers were investigated (Yao et al., 2013). Warm Mix Asphalt (WMA) has been attracting a lot of attention recently due to various advantages such as reduction in energy consumption, reduced emissions, reduced binder aging and extended construction season in temperate climates. Al-Rawashdeh and Sargand (2014) looked at the effects of water on the adhesive cohesive forces of WMA mixtures and Hot Mix Asphalt (HMA) mixtures. They found that the adhesion and cohesion energy of WMA mixtures was as great as HMA mixtures. Another study (Liu et al., 2014) looked at the anti-aging properties of asphalt binders made from different crude oils. The study focused on the impact of aging on saturates aromatics, resins, asphaltenes, penetration, softening point and molecular distribution. Results showed that saturates remained the same while the aromatics and resin decrease in quantity with aging. Aromatics and resins react with oxygen to asphaltenes which indicates a content increase, leading to a decrease in penetration and ductility. The softening point of the mixture increases while dispersity decreases. The investigation also proved that asphalt with a high activation energy and lower reaction rate coefficient has superior resistance to age performance.

Nano-clay has been used commonly in the polymer industry to enhance asphalt's mechanical and physical properties such as stiffness, toughness, strength and thermal stability (Lee et al., 2005). The primary use of nano particles as modifiers in asphalt binders has been to enhance rutting and cracking resistance (You et al., 2011; Goh et al., 2011; Amirkhanian et al., 2010). In the asphalt industry many organic and non-organic modifiers have been used to lower bitumen viscosity, reducing carbon emissions, lowering energy consumption and improving bitumen workability. Traditionally, the purpose of applying modifiers has been mainly to extend the asphalt's high and low temperature performance grade or to enhance aging resistance of asphalt binder. In addition, the environmental concerns of the asphalt industry led to the promotion of green asphalt technologies. These new technologies can lead to a reduction in the carbon footprint of pavements by the use of Warm Mix Asphalt (WMA), Half-Warm Mix Asphalt (HWMA) and Cold Mix Asphalt (CMA) which reduce fuel consumption and $\mathrm{CO}_{2}$ production. Some of the challenges with certain modifiers that include nanoparticles are related to agglomeration and difficulty of uniform blending due to electrostatic forces which cause the nano-particles to clog and reduce their surface area. As such, those modifiers are commonly accompanied by surfactant and flow modifiers. Carbon black has been used as a flow modifier in the polymer and adhesive industry. In this study bio-char has been used as flow modifier along with nano-clay particles. Increasing the nano-clay concentration in asphalt binder mixtures enhances the temperature susceptibility as well as increases the complex modulus and dspacing, while decreasing the phase angle (Abdelrahman et al., 2014). Yao et al. (2012) used polymer and nano-clay at concentrations of 2 and $4 \%$ respectively in an effort to reduce the oxidative aging of specific asphalt (PG 58-34). An increase in viscosity and complex shear modulus was observed when nonmodified nano-clay was added to the base asphalt. However, a decrease in viscosity and complex shear modulus was observed when polymer modified nanoclay was added to base asphalt. Furthermore, polymer modified nano-clay showed to improve rutting and fatigue cracking resistance of asphalt binder (Yao et al., 2012). Nazzal et al. (2013) observed the fundamental characterization of asphalt clay nanocomposites, which indicated that when nano-clay is added to asphalt binder, its adhesive forces are enhanced significantly while having an adverse effect on the cohesive forces. Stiffness and hardness of the asphalt binder were improved depending on the temperature and nano-clay concentration (Nazzal et al., 2013).

In this study bio-char has been used as a flow modifier/binder along with nano-clay particles in the asphalt. Bio-char (biologically derived charcoal) is the waste product from a hydrothermal process used to produce bio-binder from swine manure. This material is heavily used in the farming industry as fertilizer. Bio-char has the potential to increase conventional agricultural productivity and enhance the ability of farmers to participate in carbon markets beyond the traditional approach by directly applying carbon to soil (McHenry, 2009). Applying bio-char to the soil replaces carbon, nitrogen and most of the plant nutrients that are removed from the soil with the biomass. The carbon content in bio-char is highly stable in soil environments and may be sequestered for thousands of years. Producing bio-char from farm or forestry waste provides an impressive list of potential co-benefits, including the generation of renewable electricity, liquid biofuels, gas biofuels, activated carbon, eucalyptus oil, a large amount of heat or low-pressure steam as well as the potential of net withdrawal of carbon dioxide from the atmosphere (McHenry, 2009). The optimum bio-char production temperature in terms of carbon recovery is $500^{\circ} \mathrm{C}$. Bio-char produced under $400^{\circ} \mathrm{C}$ has a low surface area and may not be useful as an agricultural soil improver (Lehmann, 2007). 
This paper also identifies the ability of bio-char to remove hexavalent chromium ( $\mathrm{Cr}(\mathrm{VI})$ ) from run-off water from places such as gas stations and truck stops where there is a high volume of hazardous materials present. In recent years, researchers have been focusing on the removal of heavy metal ions such as $\mathrm{Cr}(\mathrm{VI})$ from solution by adsorption as an effective and economical process. Agricultural materials such as waste wool, nut wastes, tree barks, modified cotton and sawdust have been used in this procedure. $\mathrm{Cr}(\mathrm{VI})$ is known to be one of the most dangerous metal ions due to its toxicity, carcinogenic and mutagenic effects on human health. The US Environmental Protection Agency (EPA) recommended that the maximum allowable limit for $\mathrm{Cr}(\mathrm{VI})$ should be $0.1 \mathrm{mg} \mathrm{L}^{-1}$ for discharge into inland surface waters and $0.05 \mathrm{mg} \mathrm{L}^{-1}$ in potable water (EPA, 1990). Due to environmental regulations, the $\mathrm{Cr}(\mathrm{VI})$ concentration needs to be reduced to an acceptable level for discharge into sewers. Several other techniques such as precipitation (Mohan et al., 2011), ion exchange (Rivero et al., 2004), membrane separation (i.e., ultrafiltration and reverse osmosis) (Barakata and Schmidt, 2010) have been used to remove Cr(VI) from run-off water. However, these practices cannot be continued for long periods of time due to have some limitations which include the generation of toxic sludge, high operation and maintenance expenditure, high energy requirements, long treatment times and poor removal efficiencies.

\section{Materials and Methods}

In this study, it is hypothesized that the inclusion of bio-char in nano-modified asphalt binder can enhance asphalt binder's rheological properties and reduces its aging susceptibility. To test this hypothesis, rheological characteristics and Viscosity Aging Index (VAI) of nano-modified asphalt binder before and after modification with bio-char was evaluated.

\section{Rotational Viscosity (RV) Test}

The Rotational Viscometer (RV) test was conducted using the Brookfield rotational viscometer according to the ASTM D4402 standard specification. Test results were used to compare the viscosity of all un-aged samples to the viscosity of all aged samples. Tests were conducted at 150 and $175^{\circ} \mathrm{C}$ temperatures.

\section{Rolling Thin Film Oven (RTFO) Test}

Short-term aging of asphalt binder mixtures was performed using Rolling Thin Film Oven (RTFO) procedure in accordance to the ASTM D2872 standard specification. Test results were used to compare VAI of the proposed samples.

\section{Asphalt Binder}

The base asphalt in this study was a PG 64-22 asphalt binder from Sharpe Bros Inc., Division of Vecellio and Grogan in Greensboro, NC. It should be noted that PG 64-22 (Table 1) is one of the most commonly used asphalt binders in North Carolina

\section{Nano-Clay}

Cloisite-11 consists of organically modified layered silicate platelets. The surfaces of these platelets are chemically modified to allow dispersion into thermoplastic systems such as asphalt binder. Nanoclays are found naturally; hence they are environmentally safe, economical and sustainable. Nanoclay was acquired from BYK Additives and Instruments.

\section{Bio-Char Production}

Bio-char is the waste product of a thermochemical process used to convert swine manure into bio-oil (Fini et al., 2011). Bio-char is available after the filtration process. A vacuum pump is placed in a confined environment to prevent the spilling of the bio-oil. One end of a transparent hose is connected to the vacuum end of the pump and the other end of the transparent hose is connected to a glass beaker. A rubber stopper is placed in the top of the glass beaker. A sieve is then connected to a funnel, which is placed inside the rubber stopper. A sheet of filter paper is placed inside of the sieve. Bio-oil is poured over the filter paper. Vacuum pump is then switched on. When all the liquid has been pulled through the filter paper and sieve into the glass beaker, a solid material, which remains on top of the filter paper, is known as bio-char.

\section{Properties of Bio-Char}

The average particle size and $\mathrm{pH}$ value of Bio-Char are 100 micron and 6.5 , respectively. The chemical composition of the Bio-Char is given in Table 2.

\section{Mixture Design}

Due to the weight and size of the nano materials used in this study, the mixing of each sample had to be completed with caution so that no loss of nano material to the atmosphere. Nano materials (Cloisite-11 [CL-11] and Bio-Char $[\mathrm{BC}]$ ) were placed into individual aluminum cans by percentage weight of dry mass mentioned in Table 3.

Virgin $A B$ is then carefully poured into each aluminum can. Blending took place for ten minutes where an electric drill with a mixer drill bit attachment was used at a rotational speed of approximately $800 \mathrm{rpm}$. 
Table 1. Properties of base binder (PG 64-22)

\begin{tabular}{llll}
\hline Specific gravity $@ 15.6^{\circ} \mathrm{C}$ & Flash point, Cleveland open Cup, ${ }^{\circ} \mathrm{C}$ & Change in mass RTFO & Absolute viscosity at $60^{\circ} \mathrm{C}$, Pa.s \\
\hline 1.039 & 335 & -0.0129 & 202
\end{tabular}

Table 2. Chemical composition/elemental analysis of the bio-char

\begin{tabular}{ll}
\hline Elements & \% mass of Bio-Char \\
\hline $\mathrm{K}$ & 0.45 \\
$\mathrm{Na}$ & 0.11 \\
$\mathrm{Mg}$ & 0.71 \\
$\mathrm{Ca}$ & 2.23 \\
$\mathrm{Cu}$ & 0.02 \\
$\mathrm{Cr}$ & 0.00 \\
$\mathrm{Fe}$ & 0.08 \\
$\mathrm{Al}$ & 0.07 \\
$\mathrm{As}$ & 0.00 \\
$\mathrm{Cd}$ & 0.00 \\
$\mathrm{Ag}$ & 0.00 \\
$\mathrm{P}$ & 1.99 \\
$\mathrm{Mn}$ & 0.02 \\
$\mathrm{~Pb}$ & 0.00 \\
$\mathrm{Zn}$ & 0.04 \\
\hline
\end{tabular}

Table 3. Experimental mixture design

\begin{tabular}{llll}
\hline Specimen & PG 64-22 & Bio-char & Cloisite-11 \\
\hline Control & $100 \%$ & & \\
BC-3\% & $97 \%$ & $3 \%$ & \\
BC-6\% & $94 \%$ & $6 \%$ & \\
CL-11-3\% & $97 \%$ & & $3 \%$ \\
CL-11-3\% & $94 \%$ & & $6 \%$ \\
CL-11-3\%,BC-3\% & $94 \%$ & $3 \%$ & $3 \%$ \\
\hline
\end{tabular}

\section{Rheological Characteristics}

In order to determine the rheological behavior of each modified sample, 10.5 grams of each sample was poured into different aluminum chambers to gain better sampling of the entire blend. The tubes were then placed into a $30 \mathrm{~min}$ pre-heated thermosel where thermal equilibrium was attained before proceeding with the RV test. Tests were conducted at 150 and $175^{\circ} \mathrm{C}$ at speeds of 50,100 and $200 \mathrm{rpm}$. The spindle SC27 was used for testing, where the first viscosity reading was recorded after 15 minutes of shearing. Two more readings were recorded at three minute intervals (three readings for each $\mathrm{rpm}$ at a given temperature) to ensure consistency of viscosity measurements. This procedure was used for un-aged and aged samples. Each of the above mentioned samples were aged using the RTFO method (short-term aging) according to ASTM D2872. Viscosity results for both un-aged and aged samples were then compared and discussed.

\section{Sorption Procedure for Chromium Removal}

A batch sorption study was conducted to identify the optimum $\mathrm{pH}$ value for the maximum removal of
$\mathrm{Cr}(\mathrm{VI})$. The $\mathrm{Cr}(\mathrm{VI})$ stock solution of $1000 \mathrm{mg} \mathrm{L}^{-1}$ was prepared by dissolving $2.8269 \mathrm{~g}$ of $\mathrm{K}_{2} \mathrm{Cr}_{2} \mathrm{O}_{7}$ salt in $1 \mathrm{~L}$ of deionized water. This solution was then diluted using deionized water to obtain the required working concentration. The $\mathrm{pH}$ value was varied using either 15.8 $\mathrm{M} \mathrm{HNO}_{3}$ or $1 \mathrm{M} \mathrm{NaOH}$. The $\mathrm{Cr}(\mathrm{VI})$ and Bio-char were mixed using a magnetic stirrer at room temperature. The samples were then collected at specific time intervals and filtered through a $0.20 \mu \mathrm{m}$ syringe filter (Sterlitech, WA, USA). Filtered samples were stored in a glass bottle and preserved, if needed, in a refrigerator at $4{ }^{\circ} \mathrm{C}$ with a $\mathrm{pH}$ value below 2 to avoid the degradation of $\mathrm{Cr}(\mathrm{VI})$ concentration. The samples were then analyzed to measure the total $\mathrm{Cr}$ concentration using a Graphite Furnace equipped with an Atomic Absorption Spectrophotometer (GF-AAS) (Buck Scientific, model: 210 VGP) using an airacetylene flame and chromium hollow cathode lamp at a slit of $0.7 \mathrm{~nm}$ and wavelength of $358.1 \mathrm{~nm}$. Prior to the sample analysis, the GF-AAS instrument was calibrated regularly. Duplicate tests were performed for all batches and average values were used in the plot. The percentage of $\mathrm{Cr}(\mathrm{VI})$ removal was calculated based on the following equation:

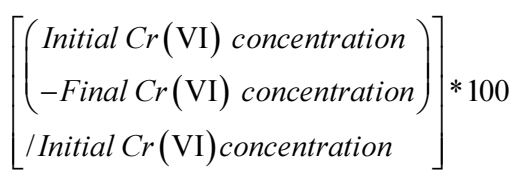

\section{Results and Discussion}

\section{Viscosity Temperature Susceptibility}

Figures la to $\mathrm{c}$ are plots of viscosity versus temperature for all samples in this study. It can be observed that at all three shearing speeds (50,100 and $200 \mathrm{rpm}$ ) used in this study, the samples that contains $6 \%$ NC (Cloisite-11) has the highest temperature susceptibility. It is also evident that the temperature susceptibility decreases as the temperature increases. The temperature susceptibility for control, 3\% bio-char and $6 \%$ bio-char are relatively close. It can be further observed that the temperature susceptibility values for samples including 3\% NC and those including 3\% NC plus 3\% BC are quite similar.

\section{Shear Susceptibility}

The shear susceptibility is illustrated in Fig. $2 \mathrm{a}$ and $\mathrm{b}$ at two different temperatures. When bio-char and nano-clay 
(Cloisite-11) are added to PG 64-22, it is evident that there is a slight decrease in viscosity as the shear rate increases. There is a slight decrease in shear susceptibility as the temperature increases. However, at a higher temperature, the viscosity still decreases as the shear rate increases.

\section{Aging Susceptibility}

The extent of age hardening can be quantified in terms of viscosity using the aging index, defined as the ratio of a rheological parameter of the aged bitumen to that of the original bitumen; high values of the ratio indicate a high degree of asphalt hardening. The Viscosity Aging Index (VAI) is used to evaluate the aging extent and is calculated by measuring the viscosity of the samples before and after short-term (RTFO) aging. It is computed according to the formula shown in Equation 1:

$$
V A I=\frac{R T F O \text { aged } \text { viscosity value }- \text { Unaged viscosity value }}{\text { Unaged } \text { Viscosity value }}
$$

Values of VAI are recorded and observed for nanomodified asphalt binder and nano/bio-modified asphalt binder (Fig. 3). The purpose of this study was to evaluate the effect of bio-char on the aging susceptibility of asphalt binder. As visualized in Fig. 3 , when 3 and $6 \%$ bio-char is added to asphalt binder, little to no impact was made in the aging index. Control binder was measured at $50.898 \%$, while 3 and $6 \%$ bio-char added to asphalt binder resulted in 50.267 and $47.181 \%$, respectively. The results of nano-modified asphalt binder were then observed at 3 and $6 \%$ Cloisite- 11 and compared to the bio-modified asphalt binder results. It shows that the VAI values for the mixtures including 3 and $6 \%$ Cloisite- 11 are significantly lower than all other mixtures, 39.712 and $27.119 \%$ VAI respectively. However, with $3 \%$ Cloisite-11 and the inclusion of $3 \%$ bio-char, the VAI observed is $29.110 \%$, which is relatively similar to the nano-modified asphalt binder sample including $6 \%$ Cloisite-11 (27.119\%). The viscosity of the nanomodified $(6 \%$ Cloisite-11) sample is significantly higher than the viscosity of the sample including $3 \%$ Cloisite-11 and 3\% bio-char (Fig. 3).

\section{Rheological Characteristics}

In Fig. $4 a$ and $b$, it is evident that the viscosity increases after the sample has been aged. However, the rate at which each individual sample has aged is dependent on the type of additive used. An increase in viscosity after aging implies that oxidation has occurred, which increases the stiffness (of the modified $\mathrm{AB}$ ) and its susceptibility to cracking and rutting. It can also be concluded that viscosity drops with the inclusion of bio-char.

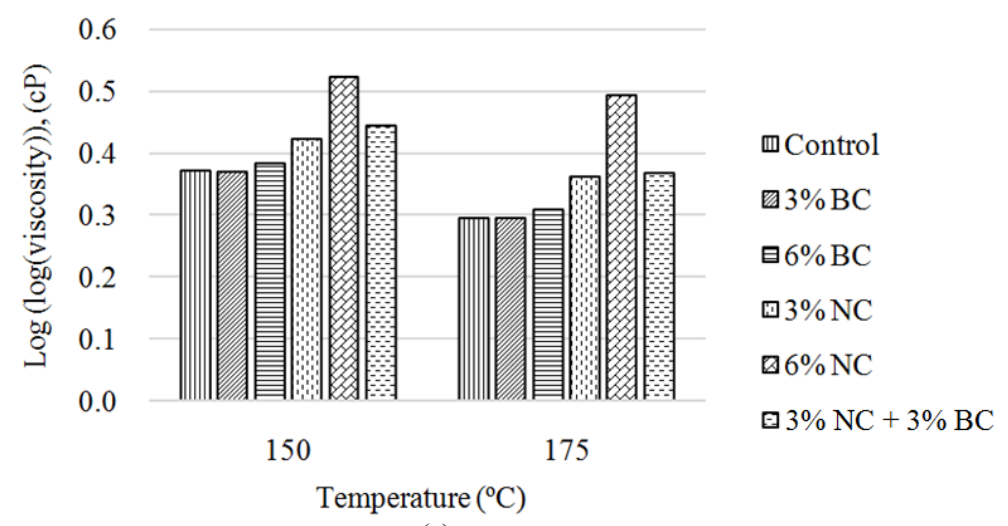

(a)

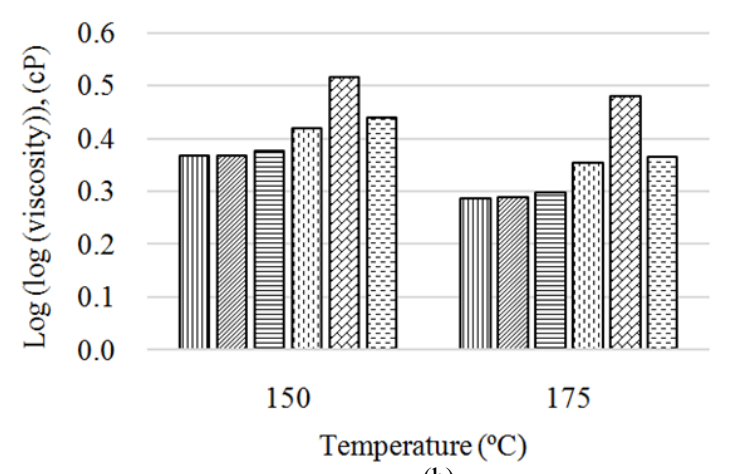

(b)

\section{Control \\ 궁 $\mathrm{BC}$ \\ 日 $6 \% \mathrm{BC}$ \\ 3N NC \\ - $6 \% \mathrm{NC}$}

曰 $3 \% \mathrm{NC}+3 \% \mathrm{BC}$ 


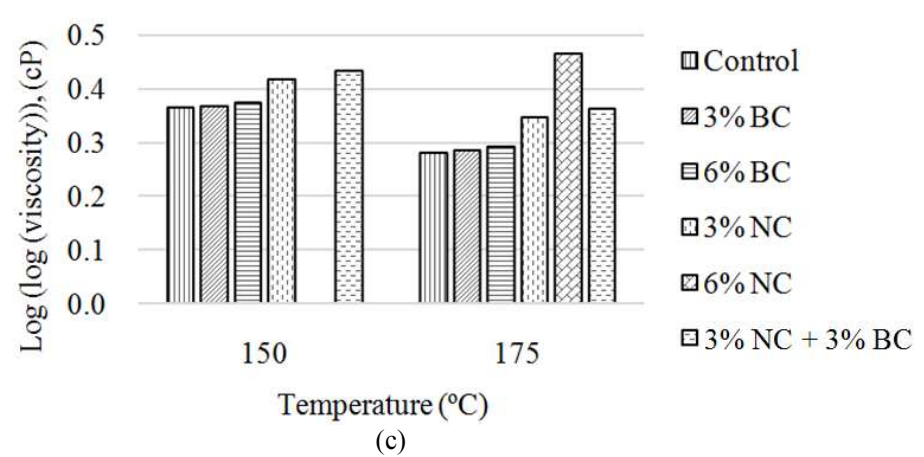

Fig. 1. (a) Viscosity temperature susceptibility at $50 \mathrm{rpm}$ (b) Viscosity temperature susceptibility at $100 \mathrm{rpm}$ (c) viscosity temperature susceptibility at $200 \mathrm{rpm}$

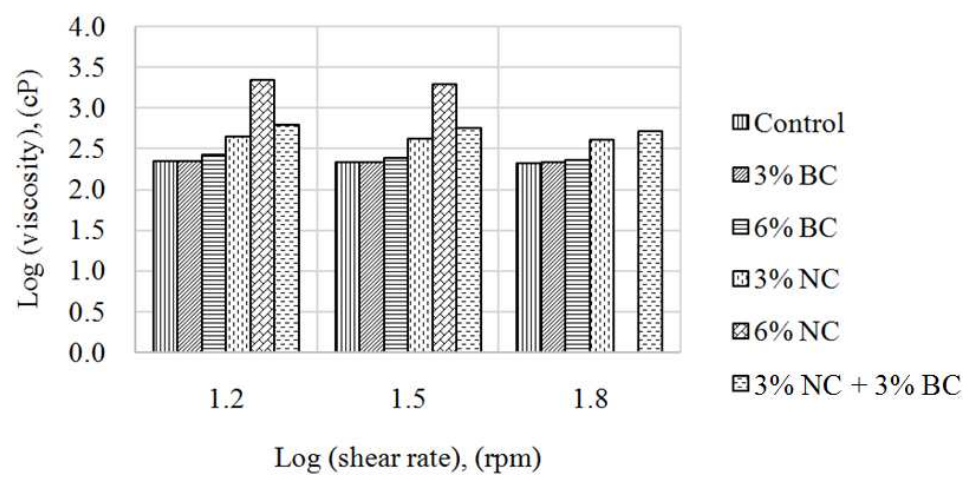

(a)

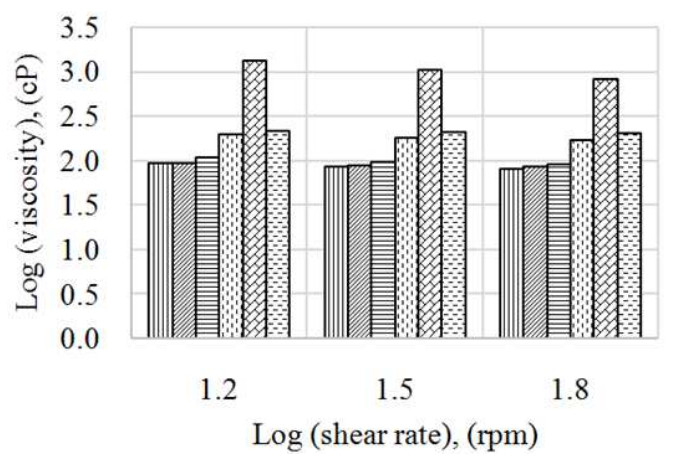

m Control

四 $3 \% \mathrm{BC}$

目 $6 \% \mathrm{BC}$

田3\% NC

$\nabla 6 \% \mathrm{NC}$

国3\% NC+3\% BC

(b)

Fig. 2. (a) Shear susceptibility at $150^{\circ} \mathrm{C}$ (b) Shear susceptibility at $175^{\circ} \mathrm{C}$

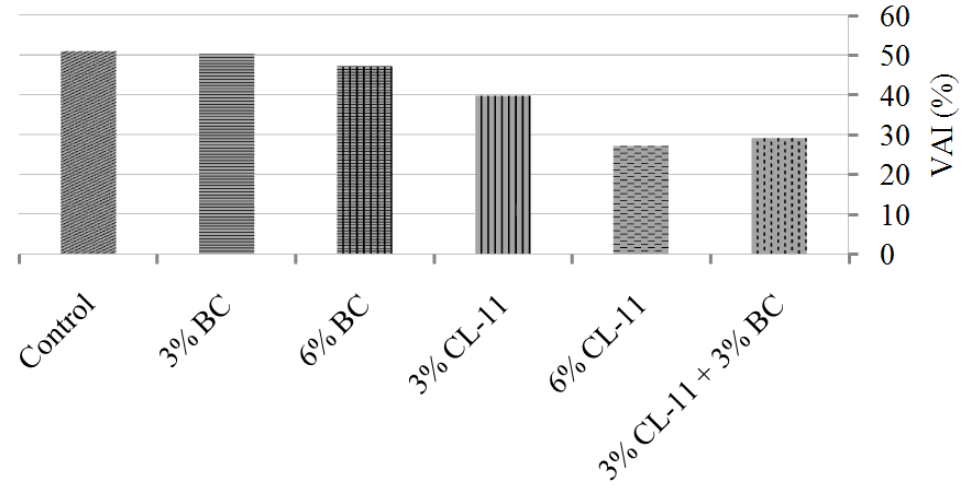

Fig. 3. Viscosity aging index for all proposed samples 


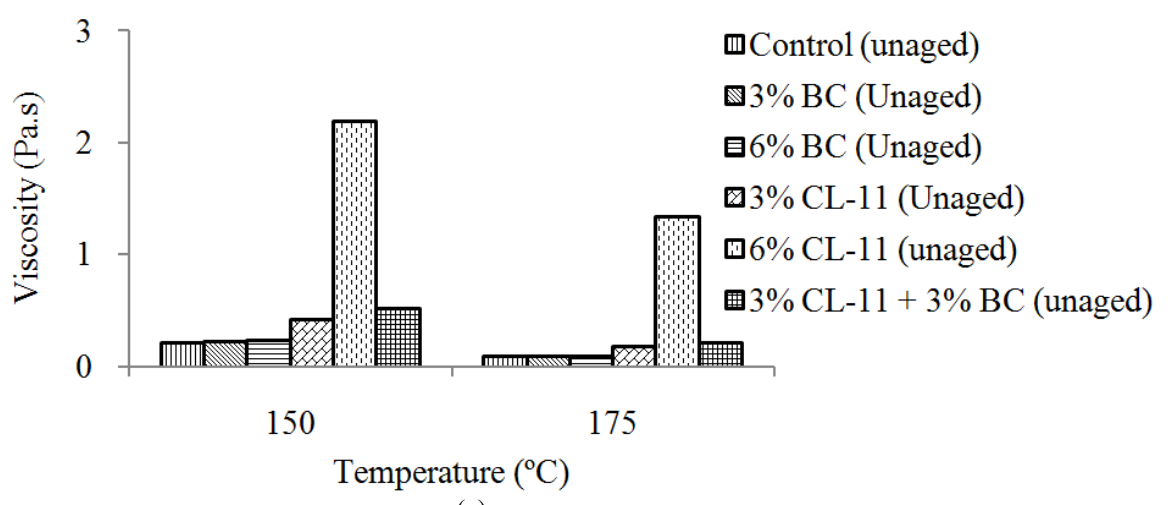

(a)

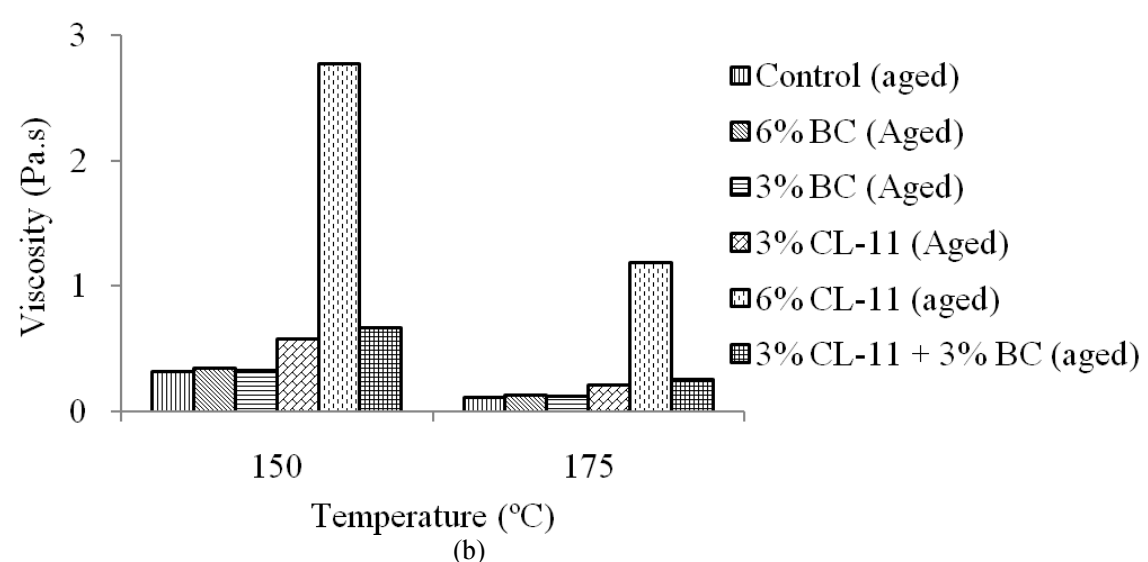

Fig. 4. (a) Rotational viscosity of un-aged samples (b) rotational viscosity of aged samples

In comparison to control binder PG 64-22, as indicated in the above graphs, the mixtures including Cloisite-11 are the most viscous. The mixture that includes $6 \%$ Cloisite-11 has an average viscosity that is significantly higher than all other samples. The mixture that includes $3 \%$ Cloisite- 11 and $3 \%$ bio-char had the next highest viscosity, however, when comparing this mixture to the mixture that includes $6 \%$ Cloisite- 11 , the surface area of these two samples is kept constant. It is therefore evident that the addition of bio-char significantly affects the viscosity of the sample.

With 6\% Cloisite-11 having significantly the highest viscosity, it is safe to say that the workability and energy consumption needed to evaluate this mixture is greater than any other mixture in this study. However, when comparing the VAI of the mixture that includes $6 \%$ Cloisite-11 to the VAI of the mixture that includes 3\% Cloisite-11 and 3\% bio-char, there is no significant difference. This indicates that the inclusion of bio-char decreases the energy consumption and workability, while the rate of aging improves significantly.

\section{Chromium Sorption Characteristics}

The $\mathrm{Cr}(\mathrm{VI})$ removal efficiency is significantly depended on the $\mathrm{pH}$ value of the solution as shown in Fig.
5. The initial optimum $\mathrm{pH}$ value was determined by varying initial $\mathrm{pH}$ values of $2,4,5.5,7$ and 9.5 with a biochar dosage of $2 \mathrm{~g} \mathrm{~L}^{-1}$ at an initial $\mathrm{Cr}(\mathrm{VI})$ concentration of $100 \mu \mathrm{g} \mathrm{L}^{-1}$. For all $\mathrm{pH}$ values tested, $\mathrm{Cr}(\mathrm{VI})$ concentrations in the reaction mixture at the second day of the experiment were higher compared to the initial $\mathrm{Cr}(\mathrm{VI})$ concentration of $100 \mu \mathrm{g} \mathrm{L}^{-1}$ except $\mathrm{pH}$ value of 9.5. Since the bio-char does not contain any $\mathrm{Cr}(\mathrm{VI})$, it is not clear why the $\mathrm{Cr}(\mathrm{VI})$ concentration increased into the reaction mixture. At a $\mathrm{pH}$ value of 2 , the concentration of $\mathrm{Cr}(\mathrm{VI})$ increased from 100 to $140 \mu \mathrm{g} \mathrm{L}^{-1}$ in 3 days and then fluctuated during the rest of the test and finally, reached a value of about $130 \mu \mathrm{g} \mathrm{L}^{-1}$. At $\mathrm{pH}$ values of 4, 5.5 and 7, the $\mathrm{Cr}(\mathrm{VI})$ concentration increased to 164,119 and $126 \mu \mathrm{g} \mathrm{L}^{-1}$, respectively, within 2 days. For the $\mathrm{pH}$ value 4 , the $\mathrm{Cr}(\mathrm{VI})$ concentration decreased sharply from 164 to $56 \mu \mathrm{g} \mathrm{L} \mathrm{L}^{-1}$ within 7 days and remained stable until the end of the experiment. A similar pattern of $\mathrm{Cr}(\mathrm{VI})$ removal was observed for the $\mathrm{pH}$ value of 5.5 with the $\mathrm{Cr}(\mathrm{VI})$ reduction from 119 to $26 \mu \mathrm{g} \mathrm{L}^{-1}$ in 6 days. At the $\mathrm{pH}$ value of 7 , the $\mathrm{Cr}(\mathrm{VI})$ concentration reduced steadily from 125 to 62 $\mu \mathrm{g} \mathrm{L}^{-1}$ from the day 2 to the day 9 , respectively. At the $\mathrm{pH}$ value of 9.5 , the $\mathrm{Cr}(\mathrm{VI})$ concentration decreased slowly from 107 to $64 \mu \mathrm{g} \mathrm{L}^{-1}$ during the test. 


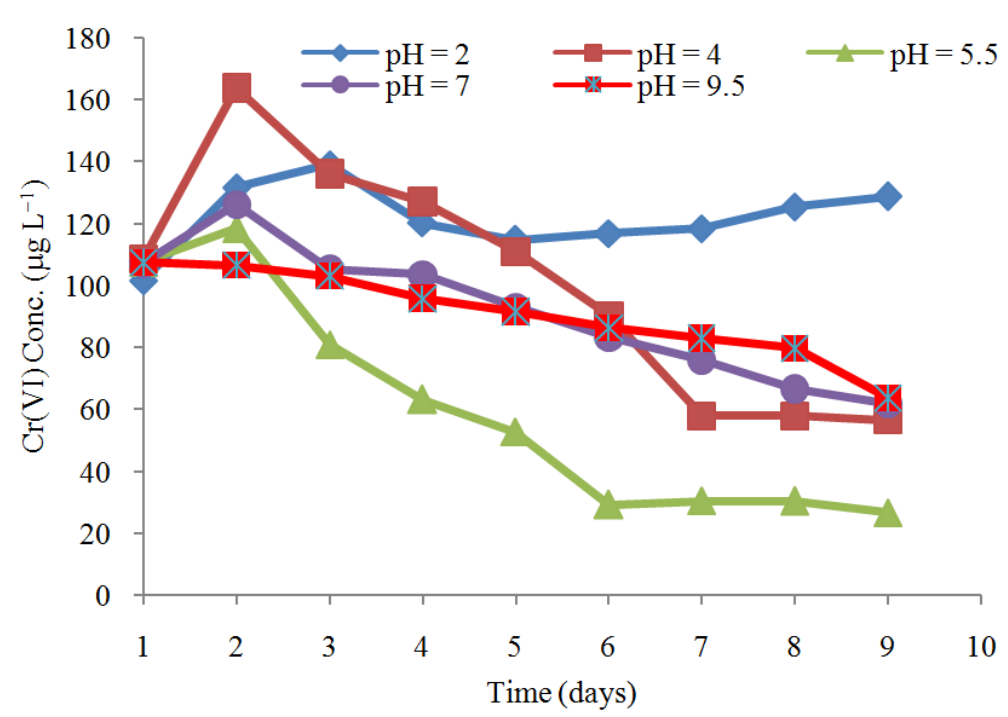

Fig. 5. Sorption of $\mathrm{Cr}(\mathrm{VI})$ at various $\mathrm{pHs}$ by using bio-char dosage of $2 \mathrm{~g}$ with an initial $\mathrm{Cr}(\mathrm{VI})$ concentration of $100 \mu \mathrm{g} \mathrm{L}$

The $\mathrm{Cr}(\mathrm{VI})$ sorption rate was higher at lower $\mathrm{pH}$ values (i.e., 4.0, 5.5) except the $\mathrm{pH}$ value of 2 compared to that of the higher $\mathrm{pH}$ values (i.e., 7.0, 9.5). The percentages of $\mathrm{Cr}(\mathrm{VI})$ removal were $0,47,75,42,40 \%$ for $\mathrm{pH}$ values of 2, 4, 5.5, 7 and 9.5, respectively. Since, the highest $\mathrm{Cr}(\mathrm{V})$ removal of $75 \%$ was observed at an initial $\mathrm{pH}$ value of 5.5, the optimum initial $\mathrm{pH}$ value was considered to be 5.5. Similar result was observed by other researchers (Yu et al., 2003).

Usually, the dominant species of $\mathrm{Cr}(\mathrm{VI})$ in solution is Hydrogen Chromate Ion $\left(\mathrm{HCrO}_{4}^{-}\right)$at an acidic $\mathrm{pH}$. This is converted to $\mathrm{CrO}_{4}{ }^{2-}$ and $\mathrm{Cr}_{2} \mathrm{O}_{7}{ }^{2-}$ ions as the $\mathrm{pH}$ value increases. The adsorption free energy change for $\mathrm{HCrO}_{4}^{-}$ ion is lower than those of $\mathrm{CrO}_{4}^{2-}$ and $\mathrm{Cr}_{2} \mathrm{O}_{7}{ }^{2-}$ ions. Therefore, $\mathrm{HCrO}_{4}{ }^{-}$is more easily adsorbed at acidic $\mathrm{pH}$ values resulting in a higher removal of $\mathrm{Cr}(\mathrm{VI})$ (Qian et al., 2012). It is also postulated that $\mathrm{Cr}(\mathrm{VI})$ can be reduced to $\mathrm{Cr}$ (III) at low $\mathrm{pH}$ values in the presence of a carbonaceous material such as bio-char. The $\mathrm{Cr}$ (III) produced is less mobile and can easily be adsorbed or precipitated as $\mathrm{Cr}(\mathrm{OH})_{3}$ on the bio-char surface. However, the reason for not removing the $\mathrm{Cr}(\mathrm{VI})$ at the $\mathrm{pH}$ value of 2.0 might be the presence of excess $\mathrm{H}^{+}$ions in the reaction mixture which can compete with the positively charge species of $\mathrm{Cr}(\mathrm{III})$ for the sorption site of bio-char. At $\mathrm{pH}$ values above 6 , the dominant $\mathrm{Cr}$ (VI) species are $\mathrm{CrO}_{4}{ }^{2-}$ and $\mathrm{Cr}_{2} \mathrm{O}_{7}{ }^{2-}$. The anionic $\mathrm{OH}^{-}$and $\mathrm{Cr}(\mathrm{VI})$ species $\left(\mathrm{CrO}_{4}{ }^{2-}\right.$ and $\left.\mathrm{Cr}_{2} \mathrm{O}_{7}{ }^{2-}\right)$ compete for the same sorption site on the bio-char surface and may result in a lower $\mathrm{Cr}(\mathrm{VI})$ removal at higher $\mathrm{pH}$ values.

\section{Conclusion}

The purpose of this study was to evaluate the effects of bio-char on the rheological characteristics and aging susceptibility of nano-modified and virgin asphalt binder as well as the removal efficiency of chromium. Bio-char (derived from swine manure) was blended at two different percentages with virgin asphalt binder (PG 6422) and nano-modified asphalt binder. Study of the rheological characteristics and aging susceptibility of the samples using 3 and $6 \%$ bio-char had little or no impact on the aging susceptibility of the asphalt binder, while it alleviate the stiffening effect of nano-clay. However, there was a significant change in both rheological characteristics and aging susceptibility when 3 and $6 \%$ nano-clay (Cloisite-11) is blended with virgin asphalt binder. Viscosity of these samples increased significantly with the increase in workability and energy consumption. These samples also resulted in the best improvement of aging susceptibility. The sample that included 3\% bio-char and 3\% nano-clay had a relatively low viscosity while the aging susceptibility was improved significantly. Considering that bio-char plays as a flow modifier alleviating the stiffening effect of nano-clay; while facilitating role of nano-clay to improve asphalt aging, it can concluded that when bio-char is mixed with nano-clay then blended with asphalt binder, the dispersion of the nano-clay is improved. In addition, bio-char has the ability to remove about $75 \%$ of $\mathrm{Cr}$ (VI) from the $\mathrm{Cr}(\mathrm{VI})$ contaminated surface runoff at a $\mathrm{pH}$ of 5.5. Accordingly, introducing a combination of bio-char and nano-clay could be a promising venue to enhance asphalt properties while promoting contaminant removal of surface runoff. Further study is undergoing to study effectiveness of bio-char on contaminant removal if used in permeable pavements and parking lots.

\section{Acknowledgement}

This research is sponsored by National Science Foundation (award \# 1150695), North Carolina A\&T State University as well as the Center for Materials 
Science and Engineering at MIT, a MRSEC supported by NSF award \# DMR-08-19762.

\section{Author's Contributions}

Each author of this manuscript made considerable contributions in all experiments, coordinated the dataanalysis and contributed to the writing of this manuscript. Drs. Fini and Abu-Lebdeh designed the research plan and organized the study.

\section{Ethics}

The authors would like to disclose that Dr. Taher M. Abu-Lebdeh (Co-author) is a member of the editorial board for the American Journal of Engineering and Applied Sciencs.

\section{References}

Abdelrahman, M., D.R. Katti, A. Ghavibazoo, H.B. Upadhyay and K.S. Katti, 2014. Engineering physical properties of asphalt binders through nanoclay-asphalt interactions. J. Mater. Civ. Eng., 26: 04014099-04014099.

DOI: 10.1061/(ASCE)MT.1943-5533.0001017

Al-Rawashdeh, A.S. and S. Sargand, 2014. Performance assessment of a warm asphalt binder in the presence of water by using surface free energy concepts and nanoscale techniques. J. Mater. Civ. Eng., 26: 803-811. DOI: 10.1061/(ASCE)MT.1943-5533.0000866

Amirkhanian, A.N., F. Xiao and S.N. Amirkanian, 2010. Evaluation of high temperature rheological characteristics of asphalt binder with carbon nano particles. J. Test. Evaluat. DOI: 10.1520/JTE103133

Barakat, M.A. and E. Schmidt, 2010. Polymer-enhanced ultra filtration process for heavy metals removal from industrial wastewater. Desalination, 256: 90-93.

EPA, 1990. EPA guidelines for water reuse.

Fini, E.H., E. Kalberer and A. Shahbazi, 2011. Biobinder from swine manure: Sustainable alternative for asphalt binder. Proceedings of the TRB 90th Annual Meeting Compendium of Papers, (MCP' 11), DVD, Transportation Research Board of the National Academies, Washington, D.C., pp: 34-53.

Goh, S.W., M. Akin, Z. You and X. Shi, 2011. Effect of de-icing solutions on the tensile strength of microor- nano-modified asphalt mixture. Construct. Build. Mater., 25: 195-200.

DOI: 10.1016/j.conbuildmat.2010.06.038

Lee, L.J., C. Zeng, X. Cao, X. Han and J. Shen et al., 2005. Polymer nanocomposite foams. Composites Sci. Technol., 65: 2344-2363. DOI: 10.1016/j.compscitech.2005.06.016

Lehmann, J., 2007. Bio-energy in the black. Front Ecol. Environ., 5: 381-387.
Liu, H., P. Hao, H. Wang and S. Adhikair, 2014. Effects of physio-chemical factors on asphalt aging behavior. J. Mater. Civ. Eng., 26: 190-197. 10.1061/(ASCE)MT.1943-5533.0000786

McHenry, M.P., 2009. Agricultural bio-char production, renewable energy generation and farm carbon sequestration in Western Australia: Certainty, uncertainty and risk. Agric. Ecosyst. Environ., 129: 1-7. DOI: 10.1016/j.agee.2008.08.006

Mohan, D., S. Rajput, V.K. Singh, P.H. Steele and C.U. Pittman, 2011. Modeling and evaluation of chromium remediation from water using low cost bio-char, a green adsorbent. J. Hazard. Mater., 188: 319-333. DOI: 10.1016/j.jhazmat.2011.01.127

Nazzal, M., S. Kaya, T. Gunay and P. Ahmedzade, 2013. Fundamental characterization of asphalt clay nanocomposites. J. Nanomech. Micromech., 3: 1-8.

Qian, H., Y. Hu, Y. Liu, M. Zhou and C. Guo, 2012. Electrostatic self-assembly of $\mathrm{TiO}_{2}$ nanoparticles onto carbon spheres with enhanced adsorption capability for $\mathrm{Cr}(\mathrm{VI})$. Mater. Lett., 68: 174-177.

Rivero, M.J., O. Primo and M.I. Ortiz, 2004. Modelling of $\mathrm{Cr}(\mathrm{VI})$ removal from polluted groundwaters by ion exchange. J. Chem. Technol. Biotechnol., 79: 822-829. DOI: 10.1002/jctb. 1049

Yao, H., Z. You, L. Li, C.H. Lee and D. Wingard et al., 2013. Rheological properties and chemical bonding of asphalt modified with nanosilica. J. Mater. Civ. Eng., 25: 1619-1630. DOI: 10.1061/(ASCE)MT.1943-5533.0000690

Yao, H., Z. You, L. Li, X. Shi and S.W. Goh et al., 2012. Performance of asphalt binder blended with nonmodified and polymer-modified nanoclay. Construct. Build. Mater., 35: 159-170. DOI: 10.1016/j.conbuildmat.2012.02.056

You, Z., J. Mills-Beale, J.M. Foley, S. Roy and G.M. Odegard et al., 2011. Nanoclay-modified asphalt materials: Preparation and characterization. Construct. Build. Mater., 25: 1072-1078. DOI: 10.1016/j.conbuildmat.2010.06.070

Yu, L.J., S.S. Shukla, K.L. Dorris, A. Shukla and J.L. Margrave, 2003. Adsorption of chromium from aqueous solutions by maple sawdust. J. Hazardous Mater. B, 100: 53-63. 